\title{
Sintering of Lunar and Simulant Glass
}

\author{
Bonnie L. Cooper
}

Robotics and Automation Group, Oceaneering Space Systems, Houston TX 77058

\begin{abstract}
Most oxygen-extraction techniques are temperature-dependent, with higher temperatures resulting in higher oxygen yield. An example is hydrogen reduction, in which the optimum process temperature is $1050^{\circ} \mathrm{C}$. However, glass-rich lunar soil begins to show the effects of sintering at temperatures of $900^{\circ} \mathrm{C}$ or lower. Sintering welds particles together due to viscous relaxation of the glass in the sample. One approach to avoid problems related to sintering, such as difficulty in removing waste material from the reactor, is to keep the soil in motion. One of several methods being studied to accomplish this is fluidized-bed processing techniques, in which the grains are kept in motion by the action of flowing reductant gas. The spent material can be removed from the chamber while still fluidized, or the fluidizing motion can continue until the material has cooled below $\sim 500^{\circ} \mathrm{C}$. Until end-to-end prototypes are built that can remove the heated soil, the most practical option is to keep the bed fluidized while cooling the waste material.
\end{abstract}

As ISRU technology advances, another option will become valuable, which is to intentionally sinter the material to a great enough extent that it becomes a brick. The free iron in lunar soil is magnetic, and ferromagnetic bricks can be manipulated by robotic systems using electromagnetic end effectors. Finally, if an electromagnetic field is applied to the soil while the brick is being formed, the brick itself will become a magnet. This property can be used to create selfaligning bricks or other building materials that do not require fasteners. Although sintering creates a challenge for early lunar surface systems, knowledge gained during prototype development will be valuable for the advanced lunar outpost.

Keywords: hydrogen reduction, fluidized bed, fluidizing, channeling, sintering, oxygen production, lunar surface systems

PACS: 89.20.Bb Industrial and technological research and development.

\section{INTRODUCTION}

Hydrogen reduction is an attractive method for extracting oxygen from lunar soils because of the low system mass requirements and the expected straightforward implementation. The chemistry is well understood, and reduction of lunar soil is one of the most thoroughly studied of the numerous lunar oxygen extraction techniques that have been proposed (Schrunk et al., 1999, 2007). NASA is developing prototype systems for hydrogen reduction to produce water vapor, which is then electrolyzed to obtain oxygen, an important consumable for life support, EVA, and propulsion. Several hydrogen reduction efforts are studying the use of fluidized bed reactors, using fluidization techniques such as recirculating gas flow, vibration, and rotation. Sintering can affect the performance of all fluidized bed techniques as well as the methods used to transfer feedstock into and out of the reactor..

\section{BACKGROUND}

Lunar simulant JSC-1 has been used in various experiments to produce oxygen via hydrogen reduction (Allen et al., 1992b; 1994b, 1994c, 1996a, 1996b, 1996c, 1996d; Gibson et al., 1994, 1999) and for sintering bricks (Allen et al. 1992b, 1994a). Several groups are now experimenting with JSC-1A and JSC-1AF, the successors of JSC-1 (Carter, 2005; Hill et al., 2006; Carpenter et al., 2006), to develop end-to-end processes with plans of achieving flightprototype design level within the next few years. The processes which have traded most favorably to date are (a) hydrogen reduction; (b) carbothermal reduction; and (c) magma electrolysis (also known as electrowinning). JSC$1 \mathrm{~A}$ is a good engineering simulant, because it mimics the grain size distribution and geotechnical properties of lunar 
soil. The percentage of glass in JSC-1A is also similar to that of lunar soil. Because sintering (described below) occurs more quickly in glass than in crystalline materials, the tendency of glass to sinter could become a design issue-especially for early lunar surface systems.

\section{WHAT IS SINTERING, AND WHY IS IT A CONCERN?}

Sintering is the compaction and bonding of particles at a temperature below their melting point. There are several ways in which particles can be sintered together (Kingery et al., 1976). The type of sintering that is most likely to occur with JSC-1A or JSC-1AF is caused by softening of glass particles (e.g. Simonds, 1973). JSC-1A and JSC$1 \mathrm{AF}$ are composed of approximately $49 \%$ glass by weight. The glass makes them good simulants for lunar soil, which also has abundant glass. However, glass sinters at a lower temperature than does a crystalline particle of the same size and shape (Simonds, 1973; Allen et al., 1994a). Experiments using Apollo-14 simulant (Wozinski et al., 1972) determined the viscosity of glasses of Apollo-14 composition, and showed that sintering can occur within minutes at a temperature of $800^{\circ} \mathrm{C}$, if the soil is packed and undisturbed (Figure 1).

Similar sintering behavior for the glasses in JSC-1A and JSC-1AF would be expected, if the particles are left undisturbed. Allen et al. (1992a, 1994a) heated compressed samples of JSC-1 (a chemically-similar predecessor to JSC-1A) to $1100^{\circ} \mathrm{C}$ to produce high-strength sintered bricks. Sintering began in a matter of minutes (Allen et al., 1992a). Other experiments at $1050^{\circ} \mathrm{C}$, conducted for three hours each on uncompressed samples, produced lightlysintered material that could be disaggregated with gentle pressure (Allen et al., 1996a). However, because empirical data on the viscosity of the glass in JSC-1A is not available, it is not possible to estimate the exact time and temperature relationships for sintering of JSC-1A or JSC-1AF. Testing must be done, both in motion and at rest, to determine when sintering happens and to what degree it is occurring. Upcoming work will attempt to quantify this with respect to different reactor designs. The goal is to develop a prototype in which the soil is easily inserted, evenly heated, and easily removed.

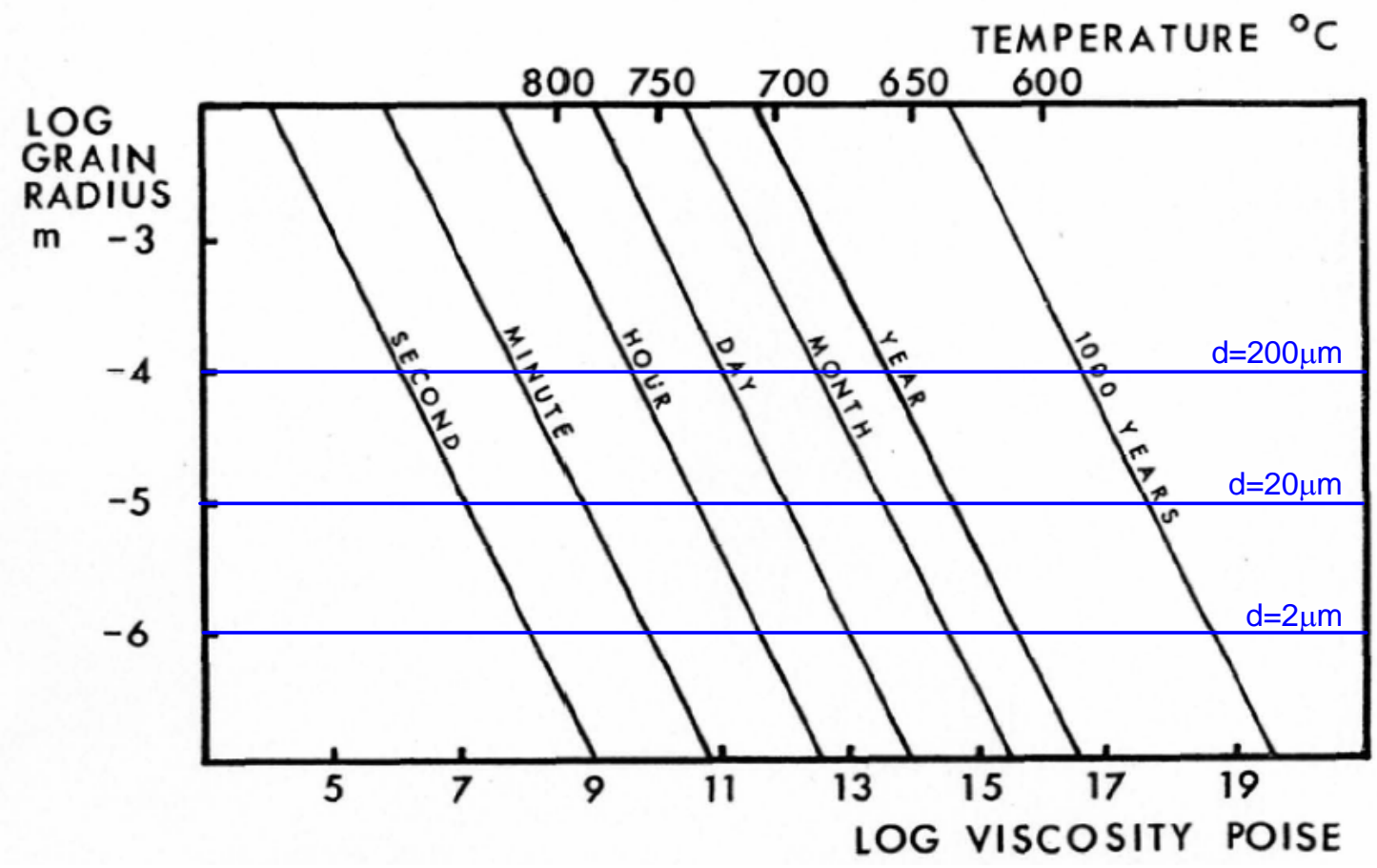

Figure 1. Graphical solution for the time necessary for incipient sintering between two glass spheres deforming by viscous flow. Temperatures plotted on viscosity are for synthetic Apollo-14-composition glass (figure from Wozinski et al., 1972). Neck radius is assumed to equal 0.2 grain radius. Surface tension is $300 \mathrm{dyne} / \mathrm{cm}$. The graph shows that particles with a radius of 14 $\mu \mathrm{m}$ (equivalent to the average size of JSC-1AF, diameter $\sim 24 \mu \mathrm{m}$ ) will begin to sinter together if they remain in contact for more than a few minutes at or above $800^{\circ} \mathrm{C}$. However, this graph assumes that the particles are not in motion, whereas one benefit of fluidizing should be to decrease the amount of time that any two grains are in contact and thus increase the operating temperature. 
Sintering affects the ease with which a spent sample may be removed from the reactor furnace at the completion of a test run, because the sintered material tends to stick to the inside wall of the furnace. And yet, all of the material from each batch should be removed —otherwise, there is a build-up of material inside the reactor which reduces its efficiency for further processing. However, sintering is not the only mechanism that adds difficulty in extracting spent material. Development work has also shown that the finest particles may stick to the filter element within the chamber. A better understanding of the sintering process may shed light on ways to mitigate the difficulties that it presents. At the same time, solutions found for addressing the sintering problem may also address other problems related to removing spent material from the reactor.

Fluidizing the sample with flowing hydrogen is intended to address the sintering challenge in addition to providing better overall conditions for efficient chemical reactions. Fluidizing has the potential for reducing the amount of sintering that occurs by decreasing the amount of time that any two particles are in contact. Perhaps more importantly, fluidization is a method of heating all of the simulant in a batch evenly. Fluidization assures that all of the material is in contact with the reductant gas, and that product water is swept out of the system so that the reaction can continue apace. However, if sintering progresses to the point that the porosity of the sample decreases, the flow of reductant gas is obstructed, and reaction efficiency is diminished. Allen et al. (1994b) described a loss of reaction efficiency due to partial melting of the sample which reduced the total surface area. Thus it is useful to explore methods of preventing or inhibiting the sintering process.

\section{HOW CAN SINTERING BE PREVENTED?}

As explained by Simonds (1973), sintering of lunar material is dependent upon the amount of time that any two particles are in contact. Thus, if it functions well, the fluidized bed serves both to mix the reactant gas with the soil, and also to minimize the time that individual grains are in contact with each other. However, in order for fluidization to successfully prevent sintering, the fluidizing action must be isotropic - every grain within the sample chamber must remain in motion. At the temperatures appropriate for hydrogen reaction $\left(900\right.$ to $\left.1050^{\circ} \mathrm{C}\right)$, time intervals of only seconds are sufficient to begin the sintering process between any two grains that remain touching.

Non-isotropic fluidization has been observed in mockups, in which the top of the cylinder (see Figure 1) is displaying vigorous motion, whereas areas can be seen near the base of the cylinder in which movement is not occurring. The end-state of uneven fluidization is channelizing, in which the heated gas creates a channel to the top of the sample and all particle motion ceases. In a series of informal observations, the change from vigorous fluidization at the top of the cylinder to a lack of motion throughout the height of the column occurred within a few seconds after a channel had formed through the entire height of the soil column.

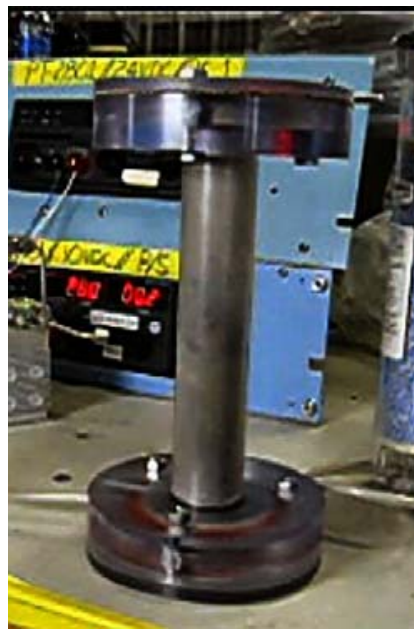

a.

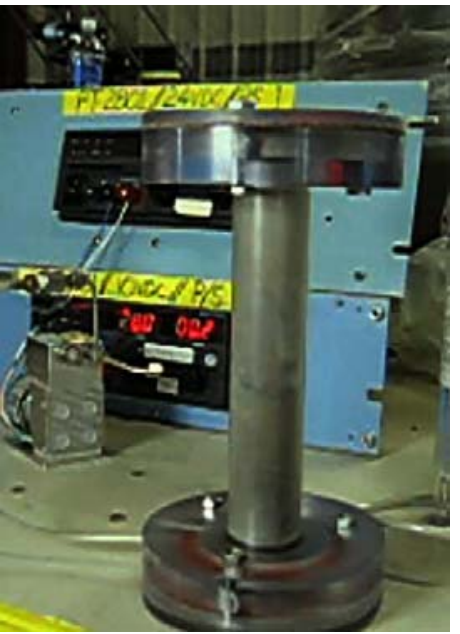

b.

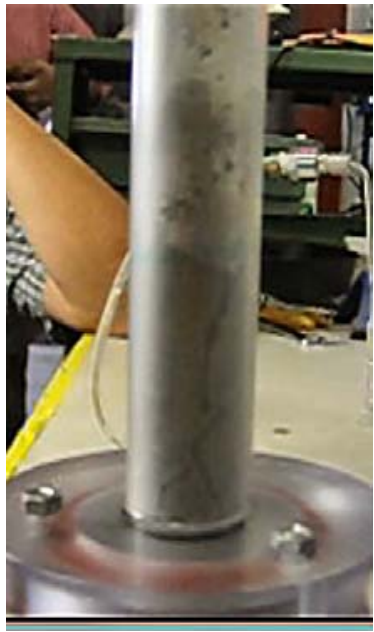

C.

Figure 2 Example of channel formation in a fluidized bed in which humid air was used. (a) Vigorous fluidizing, 31 seconds into the sequence; (b) five seconds later, fluidization ceases; (c) channel has provided a path for the gas to bypass the soil in the cylinder. 
Indirect evidence of channel formation in a closed inconel reaction chamber is available by monitoring the temperature distribution from thermocouples placed within it at diverse locations. Figure 3 shows the approximate arrangement of the thermocouples in the current version of the reaction chamber that is being tested at NASA/JSC, and the difference in recorded temperatures over time. When channelization occurs, it is logical to expect that heat transfer through the sample will be affected-and this is indeed what is observed. Figure 3(b) shows that the temperatures in the middle of the sample remain closely grouped until an abrupt change occurs in which the internal temperatures diverge. Observations of the interior of the chamber after the tests in which these data were recorded (Figure 3a) shows evidence of channels that have formed within the sample, reducing the amount of mixing within the sample (as well as the degree of contact between reactant gas and sample). Sample that is removed from the reaction chamber after a test in which channelizing is observed (Figure 4b) shows evidence of sintering. Clods of material are seen that have a concave side which matches the curvature of the channel wall. They are darker than the un-sintered sample material that surrounds them. The clods can be disaggregated with gentle pressure, a result that is in agreement with observations by Allen et al. (1996), and suggests that sintering is not severe.
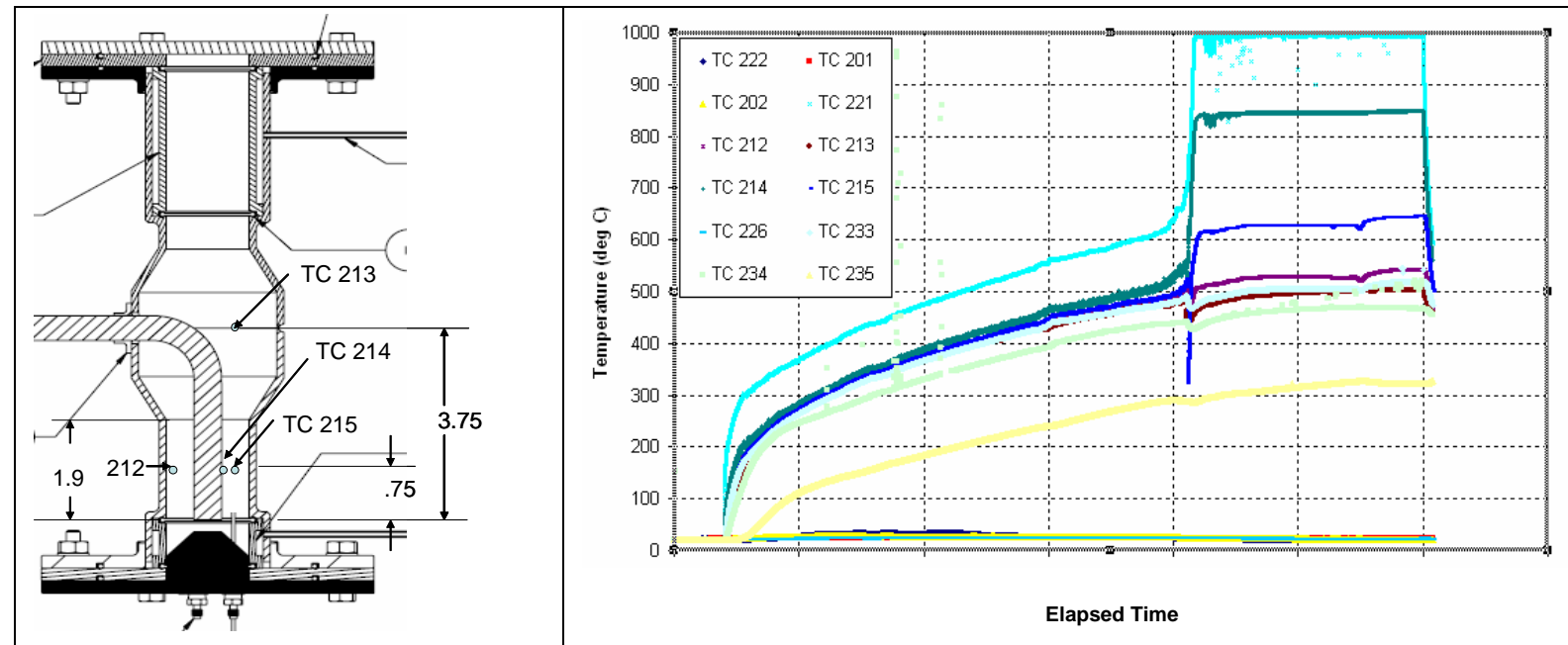

Figure 3. (a) Arrangement of thermocouples in the current version of the reaction chamber being tested at NASA/JSC. TC 212 and TC 215 are placed near the outer edge and in the middle of the sample area.(b) The thermocouples in the central portion of the chamber (TC 212 and 215) report similar temperatures during heating, followed by a rapid divergence of temperatures within a few minutes after the heater (TC 221) reaches approximately $600^{\circ} \mathrm{C}$.

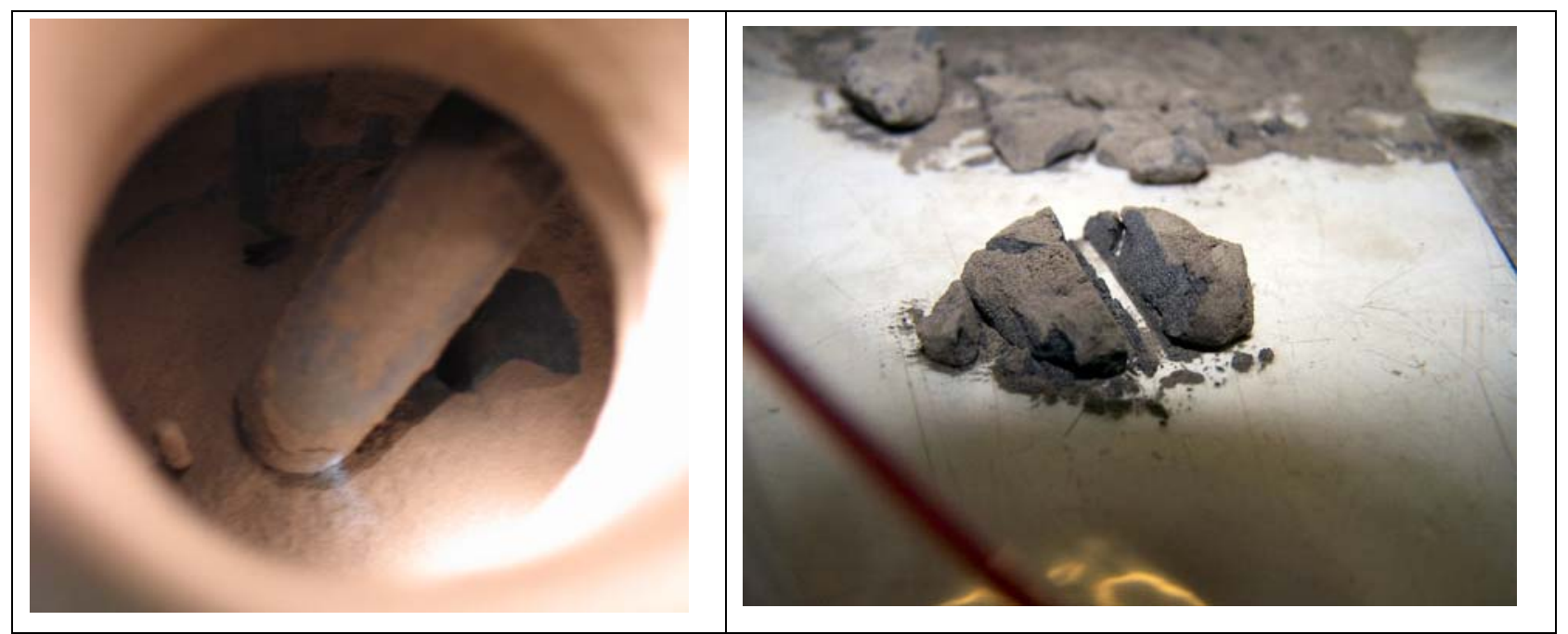

Figure 4. Relationship between channelizing and sintering is verified by observation of (a) channels in the reactor after flow has been turned off; and (b) sintered clods of material removed. 


\section{WHAT PREVENTS FLUIDIZATION?}

\section{A Wide Distribution of Grain Sizes Can Inhibit Fluidization}

Channelizing is an indication of non-isotropic fluidization, in which not all of the grains are in motion. Nonisotropic fluidization promotes sintering, and is more likely to occur in materials with a wide distribution of grain sizes. Both JSC-1AF and JSC-1A have a wide distribution of particle sizes. Calculations have shown that for a well-graded material such as JSC-1A, only $~ 70 \%$ of the particles will fluidize at the working parameters of the reactor [using hydrogen at $1000^{\circ} \mathrm{C}$ ] (Figure 5). The fluidization rate is controlled by gas flow because a higher gas flow is capable of moving larger particles. The flow rate is set according to the average particle size of the material. However, when the particles of average size are fluidizing well, the largest particles are not well-fluidized, and the smallest particles are over-fluidized, moving into the upper portion of the reactor and becoming lodged within the upper filter. Increasing the flow rate such that the largest particles fluidize will result in undesirable consequencesthe small and medium-sized particles will be forced out of the fluidized bed and into the upper filter, obstructing the flow of gas out of the chamber, and reducing the efficiency of the system. Moreover, particles trapped on the filter are not easily removed after the test run, and blockage of the filter would reduce the effectiveness of the system when deployed on the lunar surface. Figure 5 (based on a simple cylindrical reactor) shows that whether air is used at ambient conditions or hydrogen is used at $1000^{\circ} \mathrm{C}$, there is only a portion of the total sample that will fluidize at any given flow rate with this geometry. This information helps in designing reaction vessels that circumvent the tendency of particles to segregate into size classes during the fluidization process. Varying geometries are being studied to address this problem.

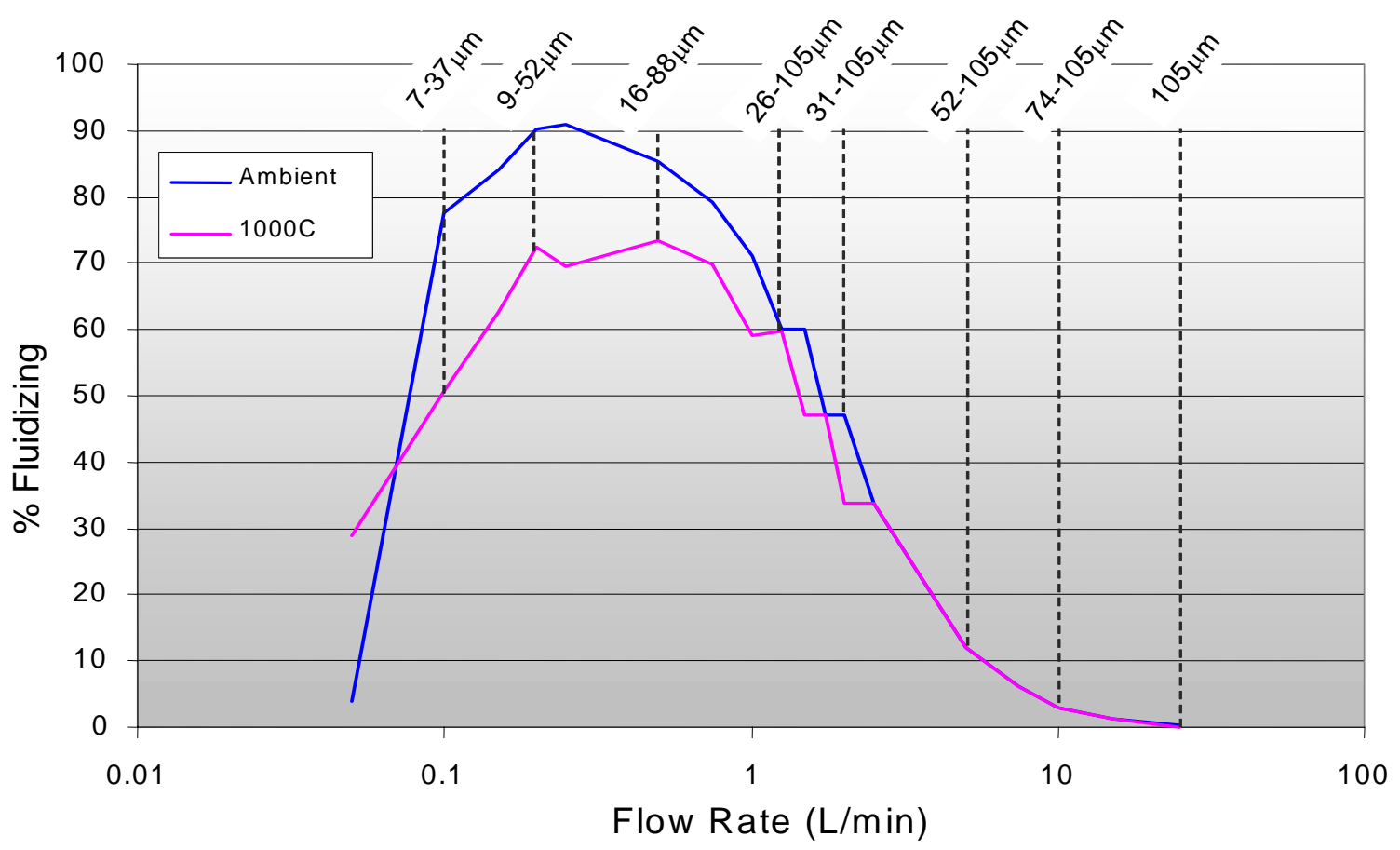

Figure 5. Because of the size distribution of particles in JSC-1AF, it is not possible to have all of the grains fluidizing at the same time in a simple cylindrical reactor. Note that steps in the curve are an artifact of data "binning" in the original grain size distribution data (the calculation assumes that all particles in a size range have the identical diameter. Design changes are planned to circumvent this problem. 


\section{Humidity}

Informal tests with mockups have shown that channelizing is more likely to occur when the fluidizing gas has a higher humidity. This was observed in tests in which a drying column was placed ahead of the air inlet. With humid air, complete channelization was observed in the mockup within 95 seconds (Figure 2); whereas when the incoming air was desiccated, channelization did not occur during the time frame of observation (tens of minutes). Because the expected result of hydrogen reduction is the production of water vapor, there is a need to understand if humidity affects channelization and subsequent sintering. Is an increase in humidity causing the channelizing in the prototype reactor, or is channelizing a result of some other systemic change? Analysis of the timing of events within the heated fluidized bed suggests that channelization (as indicated by increasing temperature differences between thermocouples at various locations within the reactor) precedes the humidity increase by a few tens of seconds. A potential solution to the problem of channelizing within the reactor is to increase the gas flow rate continuously as the temperature increases.

\section{DISCUSSION}

As work proceeds towards a flight prototype system for oxygen extraction via hydrogen reduction, additional factors must be considered that are unique to the lunar surface. A gas-fluidized bed on the Moon will require modifications to operating parameters because the fluidizing velocity of particles will change in $1 / 6$ gravity, as shown by Gibson and Knudsen (1989) (Figure 6). Models developed for vibratory fluidization in partial gravity (Nakagawa, personal communication, 2007) show that the efficiency of vibratory fluidization is reduced in 1/6 gravity, and this reduction in efficiency may also be applicable to gas-fluidized beds. Rotating reactors are also under investigation, and show promise for alleviating this problem. Hybrid systems may ultimately be developed, to exploit the best properties of rotation, gas fluidization, vibratory fluidization, and other techniques.

While fluidization may be more challenging on the Moon, sintering may be less challenging. Viscosity at temperature is decreased in materials with a low oxidation state (Cukierman and Uhlmann, 1974); thus sintering may only occur at higher temperatures in the gas-fluidized bed when lunar materials are used. However, channelizing will still occur, and may be more of a problem with lunar materials because their irregular shapes will reduce their ability to fluidize.

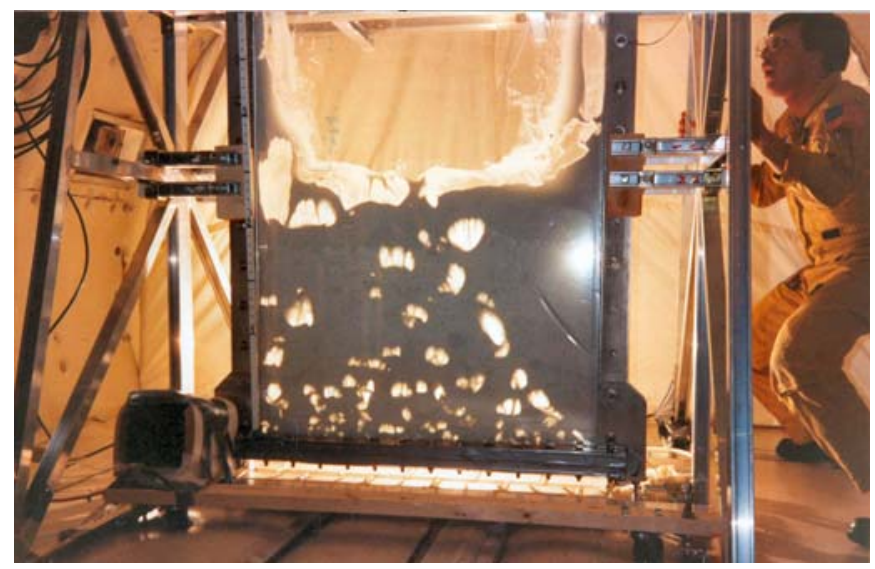

Figure 6. Fluidized-bed study in lunar gravity. Movement of gas through the fluidized bed is affected by the 1/6-g conditions, resulting in uneven movement of particles (figure from Gibson and Knudsen, 1989).

\section{SINTERED CONSTRUCTION MATERIALS}

Although sintering of lunar soil and lunar simulant is a challenging problem from the standpoint of early lunar surface systems and early use of lunar resources, the opportunities provided by the tendency to sinter have not been overlooked. The concept of "smart bricks", proposed by David McKay in 1992, takes advantage of the fact that the 
hydrogen reduction process leaves reduced (native) iron in the waste material. The concept is described by Cooper (1995), and is notionally illustrated in Figure 7.

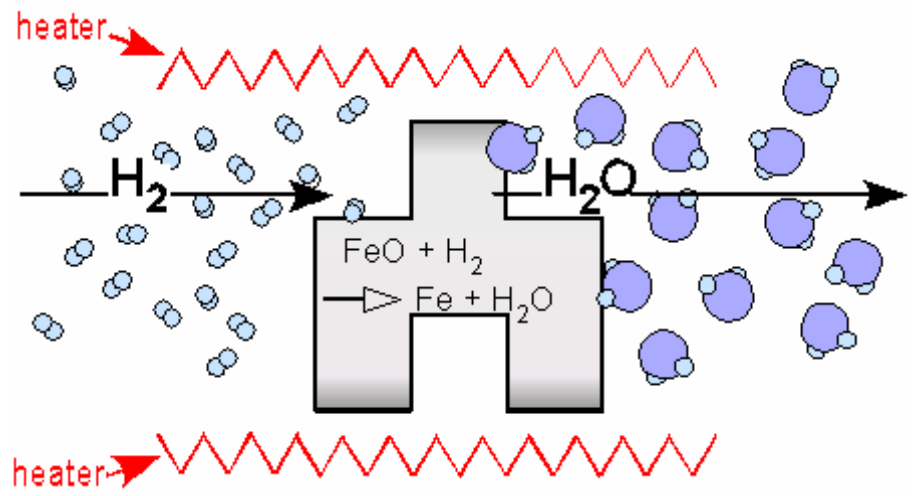

Figure 7. Reduction-assisted sintering. The native iron that is part of the sintered waste material makes it magnetically susceptible. A sintered brick formed in this way can be manipulated robotically with an electromagnetic end effector.

Concept feasibility testing was conducted by Allen et al. (1992a, 1994a) using JSC-1 and MLS-1, a simulant material that is chemically similar to Apollo soil (although it contains no glass, and is therefore less useful as an engineering simulant). Their research demonstrated that lunar simulant JSC-1, compressed and heated to $1100^{\circ} \mathrm{C}$, attained the structural strength of concrete. It has been reported that resorption of water greatly speeds up welding during compactional loading by reducing the viscosity of the glass (Sparks et al., 2000). This may account for the high strength (up to 13,790 KPa [2000 psi]) of sintered bricks made from the glass-rich JSC-1 (Allen et al. 1992a).

The concept of "smart bricks" has many possible applications for advanced lunar bases. Shown in Figure 8 is an artist's concept of a mobile robotic factory creating a lunar railroad system. The advantages of a lunar utility infrastructure enabled by a circumferential rail system at the south pole are described by Schrunk et al. (1996). McKay hypothesized that if an electromagnetic field is applied to the soil while the brick is being formed, the brick itself will become a magnet. If this can be empirically validated, first with lunar simulant and then with lunar soil, many other applications might be possible, illustrating the point that most challenges contain opportunities.

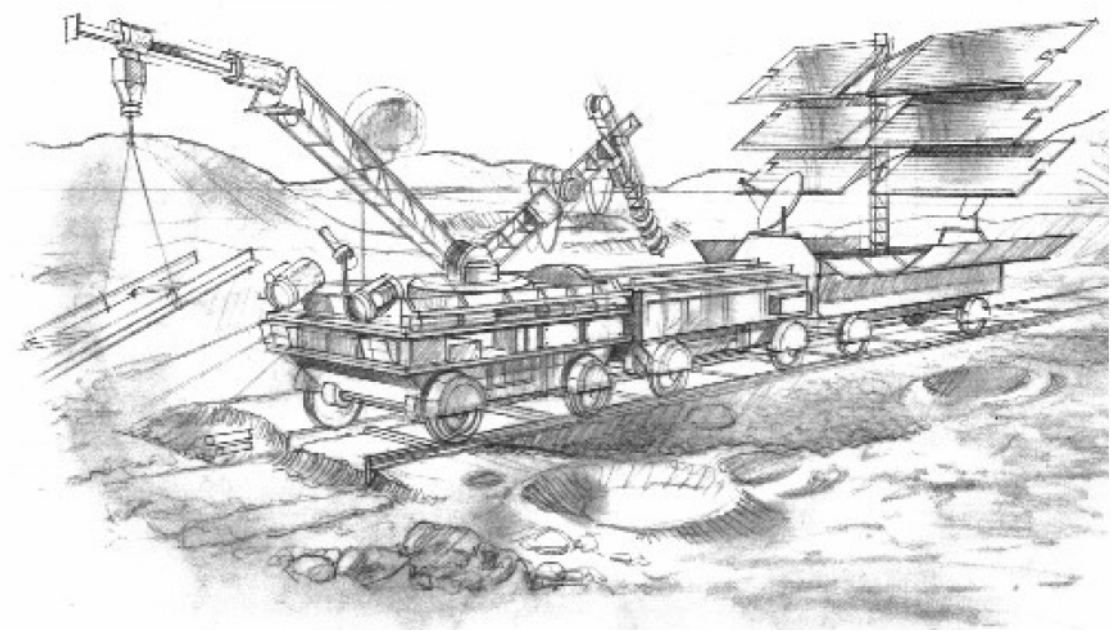

Figure 8. Artist's conception of a lunar railroad under construction. The rail sections could be formed from sintered regolith under flowing hydrogen to create "smart rails". The hydrogen reduction extracts the oxygen and leaves native iron blebs behind. The native iron makes the material magnetic, so that it can be easily handled by an electromagnetic robotic end effector. (Artwork by Paul DiMare; Figure from Schrunk et al., 2007). 


\section{CONCLUSIONS}

Hydrogen reduction research includes fluidized beds and rotating beds, as well as other methods of mixing and transporting the material. While no decision has been made regarding which technique to use, this paper describes the effect of sintering and channelizing on the efficiency of the gas fluidization process. Channelizing has the effect of allowing the reductant gas to bypass the oxidant, while sintering reduces efficiency if a significant amount of the sample is sintered to the point that porosity is reduced. Recent tests have shown that channelizing within the fluidized-bed reactor can be detected based on a relatively rapid divergence in temperatures of the thermocouples placed at various parts of the reactor. Channelization, and consequent sintering of feedstock, should be avoided in gas-solid systems such as those being developed for extraction of lunar oxygen. Variations in reactor design (e.g. Coal Gasification Study, 1983) are being studied to enhance the system's capability to operate at high temperature and high throughput. However, sintering of lunar materials can also be used to create high-strength construction materials. What seems a challenge for early lunar surface systems will become an opportunity for advanced lunar base development.

\section{NOMENCLATURE}

Fluidized Bed = A fluidized bed is formed when a quantity of a solid particulate substance (usually present in a holding vessel) is forced to behave as a fluid. In the strictest definition, fluidization is accomplished by the forced introduction of pressurized gas or liquid through the particulate medium. However, vibrating a reaction vessel has also been shown to create the same effect as that caused by a fluid. Hybrid fluidized beds have been developed, in which rotation or agitation is used to cause (or enhance) particle motion.

Sintering $=$ Sintering welds particles together due to viscous relaxation of the glass in the sample. There are other mechanisms that can cause sintering, which is used extensively in the ceramics industry. However, in the case of lunar soil and lunar simulant, softening of the glass has been shown to be the primary mechanism of sintering.

Channelizing = As gas flows through a granular material, it has the tendency to "erode" a channel in the material so that less work is needed to reach the open space above the material. This is similar to the way that streams erode deep channels (or valleys) on the surface of a planet. In a gas-fluidized bed, channelizing has the effect of allowing the reducing gas to bypass the oxidant; reducing the efficiency of the process. This phenomenon may also be referred to as defluidization.

Isotropic $=$ Having the same property in all directions. Isotropic fluidization means that all of the particles in the fluidized bed are moving at the same speed and the relative motion is the same everywhere.

Well-graded $=$ Well-graded means that there is a normal (Gaussian) distribution in particle size. Well-graded is synonymous with poorly-sorted. The mean size of JSC-1A is $151.3 \mu \mathrm{m}$, with a standard deviation of 105.2. The mean size of JSC-1AF is $22.14 \mu \mathrm{m}$, with a standard deviation of 9.99. These materials are examples of well-graded (poorly sorted) soils.

Glass $\quad=$ On average, $25 \%$ to $30 \%$ of a lunar soil sample is in the form of agglutinates-- soil grains bonded by glass. In some mature soils, agglutinates are the major constituent, comprising up to $60 \%$ of the volume of a sample. Consequently, a glass-rich material such as JSC-1A is a qualified engineering simulant for development of lunar surface systems.

\section{ACKNOWLEDGMENTS}

This work was funded by NASA Johnson Space Center through Jacobs-Sverdrup Engineering, contract NNJ05H105C. Phares Carroll (Georgia Tech) and Aaron Paz (NASA JSC) contributed significantly to this research. Thanks to Tom Simon (NASA JSC) for review and comments. The grain size distribution of JSC-1AF was measured using a Microtrac ${ }^{\mathrm{TM}}$ S3500 laser diffraction instrument, as a courtesy of Microtrac Incorporated. The measurement technique is described by Plantz (2004). 


\section{REFERENCES}

Allen, C.C., Hines, J.A., McKay, D.S., and Morris, R.V. Sintering of Lunar Glass and Basalt. In Engineering, Construction, and Operations in Space III, American Society of Civil Engineers, 1992a, pp. 1209-1218.

Allen, C.C., Morris, R.V;, Gibson, M.A; Keller, L.P.; and McKay, D.S. Lunar Resources - Oxygen from Rocks and Soil. In Geology of the Apollo 17 Landing Site, Lunar and Planetary Institute, Houston, 1992b.

Allen, C.C., Graf, J.C., and McKay, D.S. Sintering Bricks on the Moon. In Engineering, Construction, and Operations in Space IV, American Society of Civil Engineers, 1994a, pp. 1220-1229.

Allen, C.C.; McKay, D.S. ; and Morris, R.V. Lunar Oxygen Production - A Maturing Technology. Engineering, Construction, and Operations in Space IV, American Society of Civil Engineers, 1994b, pp. 1157-1166.

Allen, C.C., and Morris, R.V. Experimental reduction of lunar mare soil and volcanic glass. Journal of Geophysical Research Vol. 99 No. E-11, 1994c, pp. 23,173 - 23,185.

Allen, C.C., Morris R.V. and McKay D.S. Oxygen extraction from lunar soils \& pyroclastic glass, Journal of Geophysical Research. Vol 101 No. E11, 1996a, pp. 26085 - 26095.

Allen, C.C. and Woodell, J.M. Volcanic Glass--Oxygen Ore on the Moon, In Engineering, Construction and Operations in Space V. American Society of Civil Engineers, 1996b, pp. 756 - 761.

Allen, C.C.; Morris, R.V.; McKay, D.S.; and Klingelhoefer, G. The Production of Oxygen from Lunar Soils. in International Moon Workshop, 1996c Germany: ESA.

Allen, C.C.; Morris, R.V.; and McKay, D.S. Oxygen from Lunar Soils. in $26^{\text {th }}$ International Conference on Environmental Systems. Monterey, California: SAE, 1996d.

Carpenter, P.; Sibille, L.; Wilson, S. Development of Standardized Lunar Regolith Simulant Materials [abstract no.2279]. 37 ${ }^{\text {th }}$ Annual Lunar and Planetary Science Conference, March 13-17, 2006, League City, Texas, 2006.

Carter, J.L. McKay, D.S.; Taylor, L.A.; and Carrier W. D. Lunar Simulants: JSC-1 is Gone; The Need For New Standardized Root Simulants. In Space Resources Roundtable VI (2004), Lunar and Planetary Institute, Houston, 2005.

Cooper B.L. Smart Bricks. Space Resource News, Vol. 4, No. 2, 1995, pp. 3-4.

DOE/MC/14705-1429 Coal gasification support studies. Vol. II, Task 2. Studies of fluidized-bed reactors in coal gasification processes. Final report, November 19, 1981-August 15, 1982.

Gibson, M.A.; Knudsen, C.W.; Brueneman, D. J.; Allen, C.C.; Kanamori, H., and McKay, D.S. Reduction of lunar basalt 70035: Oxygen yield and reaction product analysis. Journal of Geophysical Research, Vol. 99 No. E5, 1994, pp. 10,887-10, 897.

Gibson, M.A.; Knudsen, C.W. Lunar Oxygen Production from Ilmenite/Fluid Particle Processing in Space. SBIR Phase II Final Report. NASA contract NAS9-17605, 1989.

Gibson, M.A.; Knudsen, C.W.; Brueneman, D.J.; Suzuki, S.; Yoshida, T.; and Kanamori, H. Recent Developments of the Carbotek Process for Lunar Oxygen Production. AIAA 92-1664, 71992.

Hill, E.; Mellin, M.J.; Deane, B.; Liu, Y.; and Taylor, L.A. Apollo sample 70051 and high- and low-Ti lunar soil simulants MLS1A and JSC-1A: Implications for future lunar exploration. Journal of Geophysical Research, Vol. 112, No. E02006 (2006).

Kingery W.D., Bowen H.K. and Uhlmann D.R. Introduction to Ceramics; Second Edition. John Wiley and Sons, New York, 1976, $1032 \mathrm{pp}$.

Nakagawa, M. Video of computer modeling of vibratory fluidized beds at 2G, 1G, and 1/6G. Personal communication, 2007.

Plantz, P.E. Evaluation of Fine Particles in Distributions and the Relationship to Microscopic Evidence. Application note SLAN-09 Rev A. Microtrac Corporation, 2004.

Schrunk, D., Sharpe, B., and Cooper, B. Concept for a permanent lunar utilities system. The 1996 5th International Conference on Engineering, Construction, and Operations in Space. Part 2 (of 2), Albuquerque, NM, USA, 06/01-06/96; pp. 935-941. 1996.

Schrunk, D., Sharpe, B., Cooper, B., and Thangavelu, M. The Moon: Resources, Future Development and Colonization. 466 pp. ISBN 0-471-97635-0. Wiley-Praxis, 1999.

Schrunk, D., Sharpe, B., Cooper, B., and Thangavelu, M. The Moon: Resources, Future Development, and Settlement. 2nd Edition. ISBN 978-0-387-36055-3. Springer-Praxis, in press, 2007.

Shirley F., Buoni C., Lennon J.W., Mezey E.J. and Weller A.E. A preliminary design concept for a lunar sintered regolith production facility. Battelle, Columbus, Ohio, 1989.

Simonds C.H. (1973) Sintering and hot pressing of Fra Mauro composition glass and the lithification of lunar breccias. American Journal of Science, 273, pp. 428-439.

Sparks, R.S.J.; Tait, S.R.; and Yanev, (XXXX) Dense welding caused by volatile resorption. 